Sharif University of Technology
Scientia Iranica
Transactions E: Industrial Engineering
SCIENTIA
IRAN I CA

\title{
An integrated model for supplier location-selection and order allocation under capacity constraints in an uncertain environment
}

\author{
F. Ranjbar Tezenji, M. Mohammadi*, S.H.R. Pasandideh and M. Nouri Koupaei \\ Department of Industrial Engineering, Faculty of Engineering, Kharazmi University, Tehran, Iran.
}

Received 17 January 2015; received in revised form 3 October 2015; accepted 19 October 2015

\author{
KEYWORDS \\ Location-allocation; \\ Supplier selection; \\ Inventory \\ management; \\ Multi-objective \\ problem; \\ Meta-heuristic; \\ Multiple-Attribute \\ Decision Making \\ (MADM).
}

\begin{abstract}
Facility/supplier location-allocation and supplier selection-order allocation are two of the most important decisions for both designing and operation supply chains. Conventionally, these two issues will be discussed separately. Due to similarity and relationship between these issues, in this paper, we investigate an integrated model for supplier location-selection and order allocation problems in Supply Chain Management (SCM). The objective function is set in such a way that the establishment costs, inventoryrelated costs, and transportation costs as quantitative criteria have been minimized. As regards, the costs are uncertainty; therefore, we have considered them stochastic. This paper develops a bi-objective model for optimization of the mean and variance of costs. Also, the capacities of supplier are limited. This mixed-integer nonlinear program is solved with two meta-heuristic methods: genetic algorithm and simulated annealing. Finally, these two methods are compared in terms of both solution quality and computational time. To obtain a high degree of validity and reliability, the results of GAMS software and meta-heuristic results are compared in small sizes.
\end{abstract}

(C) 2016 Sharif University of Technology. All rights reserved.

\section{Introduction}

The purpose of Facility Location-Allocation (FLA) problem is identifying the locations of some facilities to serve a set of distributed customers and allocation of each customer to the facilities such that the total transportation costs are minimized or other objectives are satisfied. Decision making about facility allocation plays a critical role in the strategic design of supply chain networks. The strategic level in SCM includes decisions related to the number, location, and capacities of the manufacturing plants, warehouses,

\footnotetext{
*. Corresponding author. Tel.: +982188830891;

Fax: +982188329213

E-mail addresses: Ranjbarfatemeh0@yahoo.com(F.Ranjbar Tezenji); Mohammadi@khu.ac.ir (M. Mohammadi);

Shr_pasandideh@khu.ac.ir (S.H.R. Pasandideh);

Mhrdd_Nouri@yahoo.com (M. Nouri Koupaei)
}

and other facilities or the flow of materials in the logistics network. This statement establishes a clear relationship between allocation models and strategic SCM.

Many types of FLA models have been developed to find the optimal design with respect to different location objectives such as: time, costs, coverage, and access of others. The classical transportation problem satisfies demands of customers at minimum transportation cost. The incapacitated FLA problem model develops this by choosing among a number of potential sites for locating supply facilities so that the sum of transportation costs and the fixed costs of opening facilities are minimized. The incapacitated model assumes unlimited capacity for each facility, and as a result, if a facility supplies a customer, it will satisfy all the demands. Therefore, to serve a specific demand, only one facility is necessary. The capacitated facility 
allocation problem operates under the given supply capacity constraints. There are many extensions to this basic modeling framework that include multi-objective formulations, dynamic situations, etc.

Inventory management and determined inventory policy are other important issues in the SCM. Effective inventory management can play a vital role in decreasing inventory holding costs and boosting profit across different layers of the supply chain. Economic Order Quantity (EOQ) is one of the classical inventory models. EOQ determines the order quantity that minimizes total inventory holding and ordering costs. Given different conditions such as shortage allowed, discount, etc., EOQ model can be developed.

The two crucial decisions, namely facility allocation and inventory policy, are mutually dependent. For example, the transportation cost is one of the key cost components for the facility allocation problem, which depends on the frequency of inventory replenishment at facilities. This replenishment frequency is dependent on the inventory policy. The relevance between the facility allocation and inventory policy problems develops an integrated model with the FLA for which inventory problem is needed to solve network design problems.

Suppliers are a core component of supply chain because of the substantial role of their performance in quality, cost, delivery, service, etc. In achieving the objectives of a supply chain, supplier selection is one of the most critical activities of purchasing management in an SCM. The cost of raw materials and components in manufacturing industries involves a significant part of the cost of final product, sometimes up to $70 \%$ of product cost.

Supplier selection decisions are complicated by the fact that various criteria must be considered in decision making process. Some of the most important criteria include price, quality, delivery, performance history, warranties and claim policy, production facility and capacity, geographical location, and so on. These criteria are divided into qualitative and quantitative, generally. There are various methods to choose supplier based on the specified criteria such as MCDM techniques, Mathematical Programming (MP) techniques (LP, GP), Artificial Intelligence (AI) techniques, and integrated approaches (AHP, ANP, DEA).

In this study, we consider supplier as facility and develop a located-allocated model along with selectedorder allocated supplier(s) with capacity constraint, simultaneously. Specifically, we consider a firm which operates several geographically dispersed plants/stores that face specific deterministic, stationary demand and stochastic costs. The supplier location-selection-order allocation decisions for each plant are conducted at the firm level, considering a collection of sites and suppliers that meet initial criteria. We analyze the case where each plant/store operates under the assumptions of EOQ model with backordering allowed.

We consider stochastic transportation (distancebased transportation cost), establishment fix, purchasing, inventory replenishment, holding, and shortage costs as quantitative criteria for the located and selected supplier(s); allocate customers to supplier(s); and determine order quantity for each customer. Transportation, establishment fix costs, and capacity of supplier(s) are dependent on the location of supplier establish but purchasing costs are independent.

We use MODM and Goal Attainment methods to solve this model along with Lp-metric for integrated objective functions. In small size, we use GAMS software; but in medium and large sizes, we used Genetic Algorithm and Simulated Annealing to solve this mixed-integer nonlinear model. The remainder of this paper is organized as follows: section 2 reviews the literature on the topics used in this research. Section 3 presents all the details about the model we have discussed. In Section 4, we have described MODM techniques and meta-heuristic algorithms used to solve the model. In the next section, numerical examples and results are presented. Finally, section 6 gives conclusions and suggestions for future works.

\section{Literature review}

Location theory has been considered in different studies. Here, some previous studies are briefly presented. Fontan (1826) was the first researcher who raised location theory in agricultural activities [1]. But, formulation of it took place by Alfred Weber in 1909 [2]. Weber located a single warehouse by minimizing the total travel distance between the warehouse and a set of distributed customers. This problem was extended from single warehouse (facility) to multiple supply points (facility) by another research in 1963 which was a p-median location allocation problem [3]. Then, according to distribution network and the objective function (maximum/minimum), the optimal number and location of facilities were determined. In some of the past studies, facilities and demands were used through nodes or continuous space through synthetic data. In facility location problem, a network of discrete nodes was used for facilities and demands, which were solved by Hosage and Goodchild [4]. Discrete nodes for facility or demand are also used by Medaglia et al. [5], Uno et al. [6], and Yang et al. [7]. In 1982, Murtagh and Niwattisyawong [8] proposed the capacitated Facility Location-Allocation (FLA). Their model is considered to be one of the most important FLA studies focusing on capacity of facility. Another important extension regards the inclusion of stochastic components such as future customer demands and costs in facility location models [9-12]. Owen and Daskin [13] provided an 
overview of research on facility location through the consideration of time and uncertainty.

Nowadays, FLA problems in combination with supply chain approach have been considered by researchers. Among the studies done based on solution approach, Ho et al. (2008) optimized the FLA problem in a customer-driven supply chain [14]. They considered both quantitative and qualitative criteria and used the Goal Programming (GP) and Analytic Hierarchy Process (AHP) in order to maximize. Then, Melo et al. presented a comprehensive review of Facility Location and SCM [15]. In 2011, Wang et al. [16] presented Location-Allocation (LA) decisions in the two-echelon supply chain with both profit and cost objectives. Ahmadi Javid and Nader Azad proposed a novel model to simultaneously optimize location, allocation, capacity, inventory, and routing decisions in a stochastic supply chain system [17]. Yu-Chung Tsao et al. applied an integrated facility location and inventory allocation problem for designing a distribution network with multiple distribution centers and retailers [18]. Amin and Zhang [19] used a multi-objective facility location model for closed-loop supply chain network under uncertain demand and return.

Weber and Current [20] represented the relationship between the facility location and supplier selection decisions. Research on supplier evaluation and selection in the context of purchasing strategy can go back to the early 1960s. There is a lot of research in this area, including conceptual and empirical studies. Weber et al. [21] provided a review of 74 articles related to supplier selection since 1966 . This research categorized the models with respect to the solution methodologies used/developed. Degraeve et al. [22] examined some existing supplier selection models with respect to their efficiency. Minner [23] reviewed multi-supplier inventory models, which focused on the specification of the inventory policy of each store under the assumption of multi-sourcing. Aissaoui et al. [24] provided an extensive review focusing on supplier selection and order lot size modeling. Burcu et al. [25] Proposed an integration of strategic and tactical decisions for vendor selection under capacity constraints, (They developed an integrated location-inventory model with distancebased transportation costs and capacity constraints.) In their research, they noted that relatively little research had been devoted to developing mathematical programming models to address the supplier selection problem [26-28]. The research on the theory of integrated location-inventory problems is relatively new. The theory aims at investigating the interaction between the strategic facility location and tactical inventory decisions. Some research emphasizes the inclusion of inventory costs in network design problems, e.g. $[29,30]$.

For solving FLA in SCM, numerous algorithms have been designed, involving branch-and-bound algorithms [31], branch-and-cut [32,33], Lagrangian relaxation [34,35], decomposition techniques [36,37], tabu search [38,39], genetic algorithms [40,41], simulated annealing [42,43], and scatter search [44,45]. In some cases, the development of a heuristic procedure combines different techniques. This is the case, for example, for Jang et al. [46] who use Lagrangian relaxation and a genetic algorithm.

The structure of the paper is as follows. Problem assumptions are discussed in the 'Problem description' section. In the 'Methods' section, the mathematical model is described; it is tested in a real case in the 'Results and discussion' section. Concluding remarks are in the 'Conclusions' section.

\section{Problem description and the proposed model}

In this paper, a two-echelon supply chain consisting of supplier as facility and plants/stores of a firm is represented. Capacity of supplier is limited. Also, in the context of capacitated supplier location-allocation, we consider transportation cost (fixed and variable) and establishment cost and in the context of supplier selection and order allocation, we consider the overall logistical costs including not only the purchasing costs considered in traditional models, but also the transportation (fixed and variable), inventory replenishment, holding, and [25] shortage costs.

This paper develops a bi-objective supplier location-selection-order allocation that determines inventory policy of each plant/store (when and how much to order at each plant/store) to minimize total variance and mean of the mentioned costs.

This proposed mixed-integer nonlinear programming model is solved by the following important decisions:

1. How many and which suppliers should be selected to meet the demand?

2. Which site(s) should be allocated to this (these) supplier $(\mathrm{s})$ ?

3. Which plants/stores should be allocated to this (these) supplier(s)?

4. How much should each plant/store order from this (these) supplier(s)?

\subsection{Assumptions}

To develop a mathematical model, we first present the assumptions and notations, respectively. The main assumptions considered in the problem formulation are as follows:

- All demands of plants/stores are satisfied by the supplier(s); 
- All candidate suppliers and sites meet initial criteria;

- Each plant/store operates under the assumptions of the EOQ Model with backordering allowed;

- Repletion of each plant/store is done by a single supplier and holds inventory to meet the deterministic stationary demand;

- Capacity of supplier is limited and dependent on establishment site and ability of supplier;

- Fixed and variable transportation costs are dependent on establishment site and supplier;

- Except for fixed dispatch (transportation) cost, all costs are stochastic.

\subsection{The notations of the model}

Sets:

$I: \quad$ Set of plants/stores $i \in I=\{1, \ldots, m\}$

$J$ : $\quad$ Set of candidate suppliers $j \in J=$ $\{1, \ldots, n\}$

$K: \quad$ Set of candidate sites $k \in K=\{1, \ldots, l\}$

\section{Parameters:}

$D_{i}: \quad$ Annual demand of plant/store $i$

$b_{i}$ : $\quad$ Amount of backordering allowed for each plant/store $i$

$d i_{i k}: \quad$ Distance between plant/store $i$ and site $k$

$P_{j k}: \quad$ Capacity of supplier $j$ at site $k$

$h_{i}$ : $\quad$ Inventory holding cost rate for each unit of inventory at plant/store $i$

$k_{i}$ : $\quad$ Fixed ordering (inventory replenishment) cost of plant/store $i$

$s_{i}: \quad$ Shortage cost rate for each unit of commodity at plant/store $i$

$c_{j}: \quad$ Per-unit (purchasing, handling, etc.) cost offered by supplier $j$

$f_{j k}: \quad$ Fixed cost of establishment supplier $j$ at site $k$

$r_{i j k}: \quad$ Per-mile (distance-based transportation) cost to plant/store $i$ from supplier $j$ is established at site $k$.

$t_{i j k}: \quad$ Fixed dispatch (transportation) cost to plant/store $i$ from supplier $j$ establish at site $k$.

${ }^{*} \mu$ : The prefix indicates the mean of costs.

$\mu h_{i}$ : Mean of inventory holding cost rate for each unit of inventory at plant/store $i$.

${ }^{*} \sigma$ : $\quad$ The prefix indicates the standard deviation of costs, such as

$\sigma h_{i}: \quad$ standard deviation of inventory holding cost rate for each unit of inventory at plant/store $i$.

\section{Decision variables:}

$x_{j k}= \begin{cases}1 & \text { if supplier } j \text { is established at site } k \\ 0 & \text { otherwise }\end{cases}$

$y_{j k}= \begin{cases}1 & \text { if supplier } j \text { is established at site } k \\ \text { is allocated to plant/store } i & \\ 0 & \text { otherwise }\end{cases}$

$Q_{i}=\quad$ order quantity of plant/store $i$

$T_{i}=\quad D_{i} / Q_{i}$, Order interval.

\subsection{Model}

$\operatorname{Min} Z 1=\sum_{i=1}^{m} \sum_{j=1}^{n} \sum_{k=1}^{l}\left(\mu c_{j} \cdot D_{i}\right.$

$$
\begin{aligned}
& \left.+\left(\frac{t_{i j k}+\mu_{i j k} \cdot d i_{i k}}{Q_{i}} D_{i}\right)\right) y_{i j k} \\
& +\sum_{i=1}^{m}\left(\frac{\mu k_{i} \cdot D_{i}}{Q_{i}}+\mu s_{i} \frac{b_{i}}{2 Q_{i}}+\mu h_{i}\left(\frac{\left(Q_{i}-b_{i}\right)^{2}}{2 Q_{i}}\right)\right) \\
& +\sum_{j=1}^{n} \sum_{k=1}^{l} \mu f_{j k} \cdot x_{j k},
\end{aligned}
$$

$\operatorname{Min} Z 2=\sum_{i=1}^{m} \sum_{j=1}^{n} \sum_{k=1}^{l}\left(\left(\sigma c_{j} \cdot D_{i} \cdot y_{i j k}\right)^{2}\right.$

$$
\begin{aligned}
& \left.+\left(\left(\frac{\sigma r_{i j k} \cdot d i_{i k}}{Q_{i}}\right) D_{i} \cdot y_{i j k}\right)^{2}\right) \\
& +\sum_{i=1}^{m}\left(\left(\frac{\sigma k_{i} \cdot D_{i}}{Q_{i}}\right)^{2}+\left(\sigma s_{i} \frac{b_{i}}{2 Q_{i}}\right)^{2}\right. \\
& \left.+\left(\sigma h_{i}\left(\frac{\left(Q_{i}-b_{i}\right)^{2}}{2 Q_{i}}\right)\right)^{2}\right) \\
& +\sum_{j=1}^{n} \sum_{k=1}^{l}\left(\sigma f_{j k} \cdot x_{j k}\right)^{2}
\end{aligned}
$$

s.t. :

$\sum_{j=1}^{n} x_{j k} \leq 1 \quad \forall k \in K$,

$\sum_{k=1}^{l} x_{j k} \leq 1 \quad \forall j \in J$,

$\sum_{k=1}^{l} \sum_{j=1}^{n} y_{i j k}=1 \quad \forall i \in I$, 


$$
\begin{aligned}
& y_{i j k} \leq x_{j k} \quad \forall i \in I, \forall j \in J, \forall k \in K, \\
& \sum_{i=1}^{m} D_{i} y_{i j k} \leq p_{j k} x_{j k} \quad \forall j \in J, k \in K, \\
& x_{j k} \in\{0,1\} \quad \forall j \in J, k \in K, \\
& y_{i j k} \in\{0.1\} \quad \forall i \in I, \forall j \in J, \forall k \in K, \\
& Q_{i} \in R^{+} \quad \forall i \in I .
\end{aligned}
$$

The first objective function is aimed at minimizing the mean of annual total cost, which includes (i) purchasing costs, (ii) fixed dispatch and distance-based transportation costs from the selected site to the plant/store, (iii) inventory replenishment, shortage, and holding costs of the plants/stores, and (iv) fixed cost of establishment supplier $j$ at site $k$. The second objective function is aimed at minimizing the variance of annual mention costs (except fixed dispatch transportation cost).

Constraint (3) ensures that each site is assigned to, at maximum, one supplier. Constraint (4) ensures that each supplier is assigned to, at maximum, one site. Constraint (5) dictates that the demand of each plant/store must be satisfied. In other words, this constraint ensures that each plant/store is assigned to a supplier (repletion of each plant/store by a single supplier). Constraint (6) ensures that each plant/store is assigned to the located-selected supplier. Constraint (7) represents the throughput capacities of the suppliers. In other words, Constraint (7) relates to inflow and outflow with respect to the production capacities of the suppliers. Finally, Constraints (8) and (9) ensure integrality, whereas Constraint (10) ensures non-negativity.

\section{The proposed solution method}

The model developed in Section 3.3 is a constrained multiple-objective problem. Multiple-objective problems are concerned with the optimization of multiple (vector of objectives $F(x)$ ), conflicting, and noncommensurable objective functions subject to constraints representing the availability of multiple objective problems.

A multi-objective optimization problem can be formulated as:

$$
\begin{aligned}
& \operatorname{Min}\left\{F_{1}(x), F_{2}(x), \ldots, F_{q}(x)\right\} \\
& X \in R^{n}
\end{aligned}
$$$$
\text { s.t. }
$$$$
X \in x,
$$

where the integer $p \geq 2$ is the number of objectives and the set $x$ is the feasible set of decision vectors. In multiobjective optimization, there does not usually exist a feasible solution that minimizes all objective functions simultaneously. Therefore, attention is paid to the Pareto-optimal solutions that cannot be improved in any of the objectives without degrading at least one of the other objectives. There are different ways for solving MOPS such as MODM techniques, NSGA-II, MOPSO, SPEA-2, etc.

In this research, MODM techniques are used to convert the original problem with multiple objectives into a single-objective optimization problem.

\subsection{MODM techniques}

Various methods that are available to solve multiobjective programming models are classified in four categories. The methods in the first category do not have to get primitive information from decision makers and consist of individual optimization, the Lpmetrics/global criteria, the Maxi-Min, and the filtering/displaced ideal solution (DIS). The methods in the second category consist of the goal programming, the lexicography/preemptive optimization, converting of objectives into constraints, the goal attainment, and the utility function that require primitive information from the decision maker. The methods of the third category include Geoffrion method, satisfactory goals method, and the STEM method and require reflection on the act with decision makers. The methods of the fourth category need information from the decision maker at the end of solution. The multi-criteria simplex method, the minimum deviation method, and the De Novo programming are placed in this category [25]. The selected MODM methods to solve the model include the Goal Attainment and Lp-metric.

\subsubsection{Goal attainment method}

The method described here is the Goal Attainment method of Gembicki [47]. It involves expressing a set of design goals, $\mathbf{F}^{*}=\left\{\mathbf{F}_{1}^{*}, \mathbf{F}_{2}^{*}, \ldots, \mathbf{F}_{q}^{*}\right\}$, which are associated with a set of objectives, $F(x)=\left\{F_{1}(x)\right.$, $\left.F_{2}(x), \ldots, F_{q}(x)\right\}$. The problem formulation allows the objectives to be under- or over-achieved, enabling the designer to be relatively imprecise about initial design goals. A vector of weighting coefficients $w=$ $\left\{w_{1}, w_{2}, \ldots, w_{q}\right\}$ controls the relative degree of underor over-achievement of the goals. It is expressed as a standard optimization problem using the following formulation:

Minimize $Z$

s.t.

$$
F_{i}(x)-w_{i} z \leq F_{i}^{*} \quad i=1,2, \ldots, q,
$$

where $Z$ is a scalar variable unrestricted in sign, and 
the weights $w=\left\{w_{1}, w_{2}, \ldots, w_{q}\right\}$ are normalized so that $\sum_{i=1}^{q} w_{i}=1$.

\subsubsection{Lp-metrics method}

The idea behind this method is to find the closest feasible solution to an ideal point. Some authors, such as Zeleny 1982 [48], Duckstein \& Opricovic 1980 [49], and Szidarovszky et al. 1986 [50], call this method compromise programming. The most common metrics to measure the distance between the reference point and the feasible region are those derived from the Lpmetric, which is defined by:

$$
\text { Minimize } Z=\left(\sum_{i=1}^{q}\left|\frac{F_{i}(x)-F_{i}^{*}}{F_{i}^{*}}\right|^{p}\right)^{1 / p}
$$

s.t.

\section{$X \in x$}

for $1 \leq p \leq \infty$. The value of $p$ indicates the type of metric. For $p=1$, we obtain the Manhattan metric, while for $p=\infty$, we obtain the so called Tchebycheff metric.

In this research, we used Lp-metric with $p=1$.

\subsection{Meta-heuristic algorithms}

After using MODM techniques, the model is solved by GAMS software to solve smaller sizes. Since GAMS software cannot be used in larger sizes, Genetic algorithm and simulated annealing are used to solve the obtained model.

\subsubsection{Genetic algorithm}

Genetic Algorithms (GAs) are adaptive heuristic search algorithms based on the evolutionary ideas of natural selection and genetics by Fraser 1957 [51], Bremermann 1958 [52], and Holland 1975 [53]. They are search techniques used in computing to find true or approximate solutions to optimization and search problems. GAs use techniques inspired by evolutionary biology, such as inheritance, mutation, selection, and crossover (also called recombination). The flowchart of the proposed GA is shown in Figure 1.

Chromosomes. One of the major components of the GA is the selection of chromosomes. In the proposed GA, we tried to select the best chromosomes that would give us good results and require low run-times. The binary $y_{i j k}$ and continuous $Q_{i}$ variables were considered to design two-layer chromosomes. The first layer represents variable $y_{i j k}$ and is three-dimensional, including dimensions $i, j$, and $k$. For each $i$ (plant/store) at $j$ (supplier), and $k$ (site)surfaces, there is only one cell with number 1 , and the other cells are zero. This indicates that each plant/store is allocated to only one located supplier. Different cells, containing (1), have exactly the same $j$ and $k$ indices or both indices are different. This guarantees satisfaction Constraints (3) and (4). Figure 2 shows an example of chromosomes.

$x_{j k}$ is computed from $y_{i j k}$ variables. For Constraint (7), we consider penalty function for violation of the constraints.

Initial population. A certain number of chromosomes were randomly created.

Genetic operations. The following describes the main operations of the GA, which are crossover, mutation, and selection.

- Crossover. To perform the crossover, two chromosomes (parents) must be merged. First, the parents to be combined should be identified. For this reason, we used Roulette Wheel Selection (RWS). After selection of parents, we used single-point crossover on the dimension $i$ for the first layer, see Figure 3 .

For the second layer, we used the following crossover:

$$
\begin{aligned}
& \text { Parent } 1=\left(Q_{1}^{P 1}, Q_{2}^{P 1}, \ldots, Q_{m}^{P 1}\right) \stackrel{\propto=\left(\propto_{1}, \propto_{2}, \ldots, \propto_{m}\right)}{\longrightarrow} \\
& \text { Child1 }=\left(Q_{1}^{C 1}, Q_{2}^{C 1}, \ldots, Q_{m}^{C 1}\right) \\
& \text { Parent2 }=\left(Q_{1}^{P 2}, Q_{2}^{P 2}, \ldots, Q_{m}^{P 2}\right) 0 \leq \propto \leq 1 \\
& \text { Child2 }=\left(Q_{1}^{C 2}, Q_{2}^{C 2}, \ldots, Q_{m}^{C 2}\right) \\
& Q_{i}^{C 1}=\propto_{i} Q_{i}^{P 1}+\left(1-\propto_{i}\right) Q_{i}^{P 2} \\
& Q_{i}^{C 2}=\left(1-\propto_{i}\right) Q_{i}^{P 1}+\propto_{i} Q_{i}^{P 2}
\end{aligned}
$$

After applying crossover, the first layers of children were repaired. For repair child 1, first $i$ layer after cut point parent 2 if have exactly the same $j$ and $k$ indices for (1) cell or both indices vary with $j$ and $k$ indices for (1) cell of $i$ layers before cut point parent 1 , this layer replace else don't replace, in order to end.

- Mutation. The mutation probability refers to the probability of change in any gene. Chromosomes were randomly selected for mutation. In this study, we defined two types of mutation for the first layer of chromosomes, which are illustrated in Figure 4. Mutation type was selected randomly. We used the following mutation for the second layer:

$$
\begin{aligned}
& \text { Parent }=\left(Q_{1}, Q_{2}, \ldots, Q_{m}\right) \quad \stackrel{Q_{i}^{\text {new }}=Q_{i}+\sigma N(0,1)}{\longrightarrow} \\
& \text { Child }=\left(Q_{1}, Q_{2}, \ldots, Q_{i}^{\text {new }}, \ldots, Q_{m}\right) .
\end{aligned}
$$

- Selection. Different strategies can be applied to 


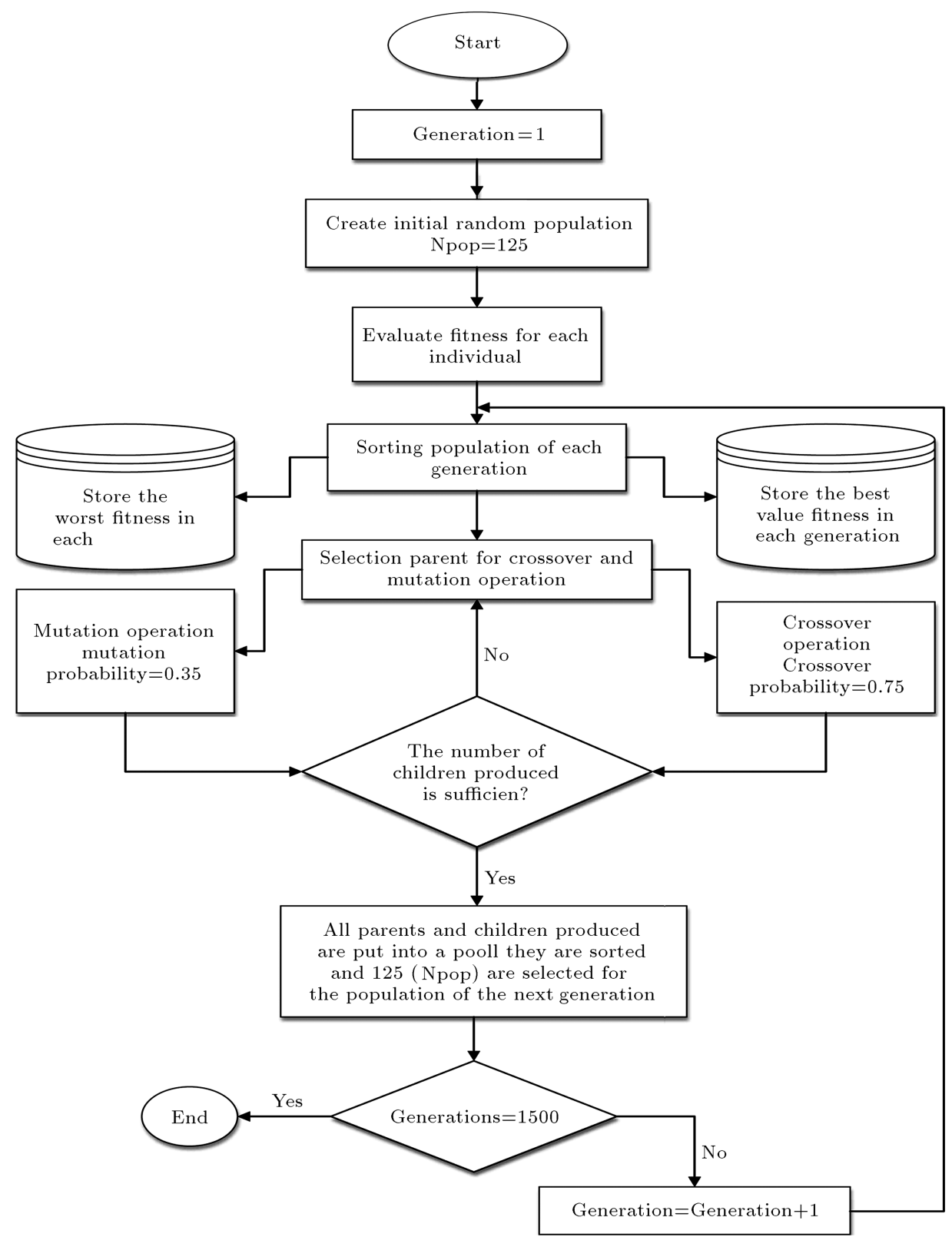

Figure 1. The flowchart of the proposed genetic algorithm.

First layer: $Y_{i j k}$

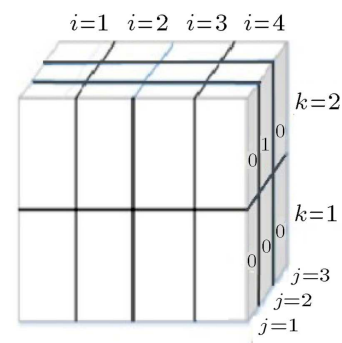

Second layer: $Q_{i}$

\section{\begin{tabular}{|l|l|l|l|}
\hline$Q_{1}$ & $Q_{2}$ & $Q_{3}$ & $Q_{4}$ \\
\hline
\end{tabular}}

Figure 2. Two layers of chromosomes: $i=4, j=3$, and $k=2$.
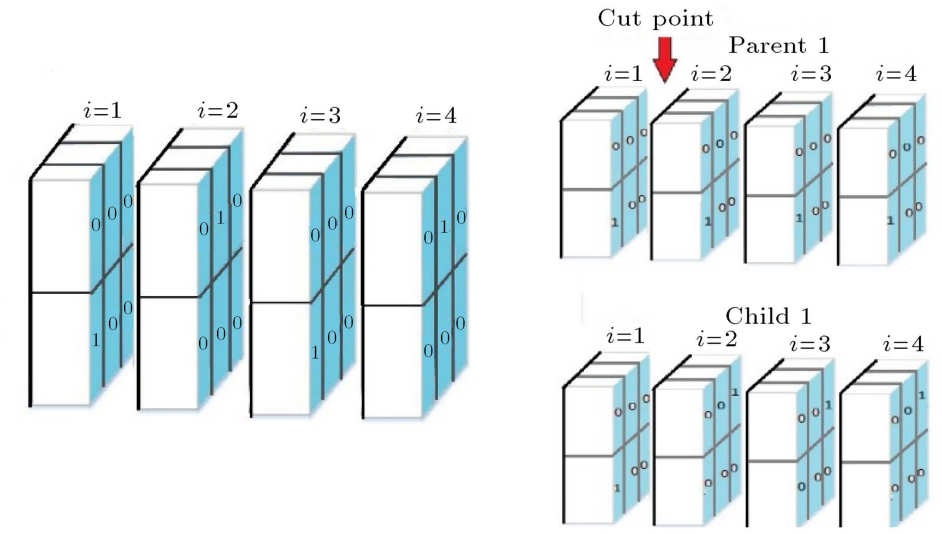

Figure 3. Crossover of the first layer (crossover was performed simultaneously in two layers). 
Type 1
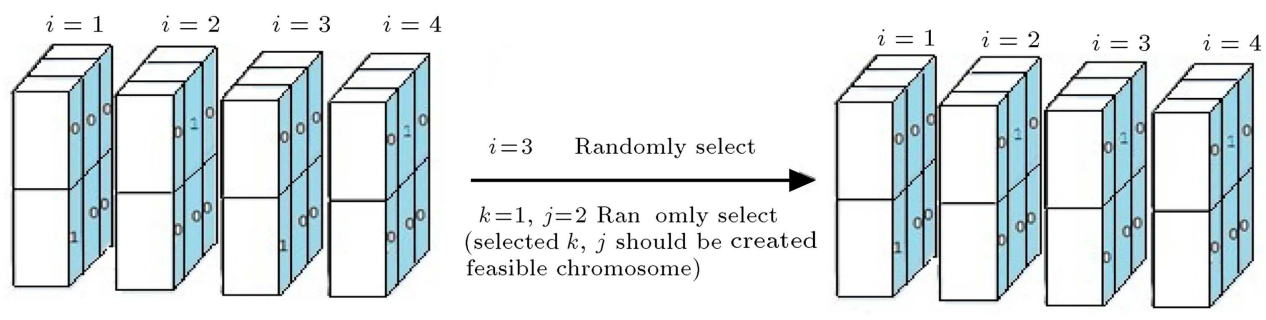

Type 2

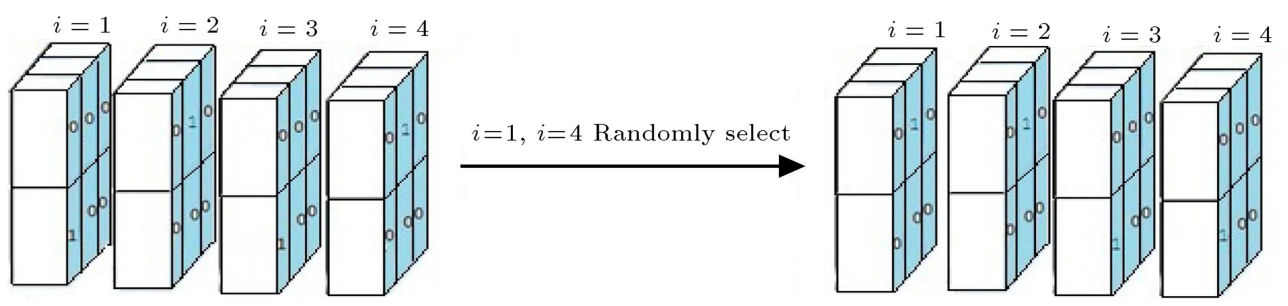

Figure 4. Mutation in the first layer (mutation was performed simultaneously in two layers).

perform the selection function, and the elite strategy was chosen in this study. First, the parents and the produced children were merged. Then, values of children's objective functions were calculated. Finally, these chromosomes were sorted according to the objective value and the best chromosomes were selected according to the population size of the next generation.

\subsubsection{Simulated annealing}

In the early 1980s, Kirkpatric Ketal (1983) [54] and, dependently, Cemy (1985) [55] introduced the concept of annealing in combinatorial optimization. Simulated Annealing (SA) is a random-search technique, which exploits an analogy between the annealing process (a process in which a metal cools and freezes into a minimum energy crystalline structure) and the search for a minimum in a more general system. The algorithm is as follows:

1. Generate an initial solution randomly and initialize the temperature parameter $\left(T_{0}=35\right)$;

2. Evaluate fitness of the initial solution $(z)$;

3. Move the initial solution randomly to a neighboring solution;

4. Evaluate fitness of the new solutions $\left(z^{\prime}\right)$;

5. Accept the new solution if (i) $z^{\prime} \leq z$; (ii) $z^{\prime} \geq z$ with acceptance probability $p=\exp \left(-\frac{\Delta z}{T}\right)$;

6. Decrease temperature with $\alpha=0.49$ rate.

In this algorithm, there are two loops: internal loop (sub-iteration $=15$ ) for search neighbors of a solution in the same temperature (form stage 3 to 5 ), and external loop (iteration $=1500$ ) for decreasing temperature. Also, to create neighbor, the mutation operation in GA is used.

\section{Results and discussion}

Parameter values were used for solving the model listed in Table 1. As shown in Table 2, the sample problems with different dimensions were used to solve the model with GAMS software (win 32, 24.1.2). For each size, three examples with different parameters

Table 1. Parameters and values.

\begin{tabular}{cc}
\hline Parameters & Values \\
\hline$D_{i}$ & Uniform $(350-1400)$ \\
$b_{i}$ & Uniform $(50-100)$ \\
$d i_{i k}$ & Uniform $(1-150)$ \\
$P_{j k}$ & Uniform $(35000-70000)$ \\
$\mu h_{i}$ & Uniform $(5-10)$ \\
$\mu k_{i}$ & Uniform $(75-300)$ \\
$\mu s_{i}$ & Uniform $(15-20)$ \\
$\mu c_{j}$ & Uniform $(0.05-0.3)$ \\
$\mu f_{j k}$ & Uniform $(50000-100000)$ \\
$\mu r_{i j k}$ & Uniform $(0.75-3)$ \\
$t_{i j k}$ & Uniform $(425-1700)$ \\
$\sigma^{2} h_{i}$ & Uniform $(1-9)$ \\
$\sigma^{2} k_{i}$ & Uniform $(25-225)$ \\
$\sigma^{2} s_{i}$ & Uniform $(1-16)$ \\
$\sigma^{2} c_{j}$ & Uniform $(0.0001-0.01)$ \\
$\sigma^{2} f_{j k}$ & Uniform $(100000-400000)$ \\
$\sigma^{2} r_{i j k}$ & Uniform $(0.01-025)$ \\
\hline
\end{tabular}

Table 2. Sample problems with different dimensions.

\begin{tabular}{cccccccc}
\hline Sample problem & $\boldsymbol{i}$ & $\boldsymbol{j}$ & $\boldsymbol{k}$ & Sample problem & $\boldsymbol{i}$ & $\boldsymbol{j}$ & $\boldsymbol{k}$ \\
\hline 1 & 1 & 2 & 3 & 8 & 2 & 3 & 5 \\
2 & 1 & 2 & 4 & 9 & 2 & 4 & 5 \\
3 & 1 & 2 & 5 & 10 & 2 & 2 & 5 \\
4 & 1 & 3 & 5 & 11 & 3 & 4 & 5 \\
5 & 1 & 4 & 5 & 12 & 4 & 2 & 2 \\
6 & 2 & 2 & 4 & 13 & 4 & 3 & 2 \\
7 & 2 & 3 & 4 & 14 & 4 & 4 & 5 \\
\hline
\end{tabular}


Table 3. Results of sample problems solved with the GAMS.

\begin{tabular}{|c|c|c|c|c|c|c|}
\hline \multirow{2}{*}{$\begin{array}{l}\text { Sample } \\
\text { problem }\end{array}$} & \multicolumn{2}{|r|}{$Z 1$} & \multicolumn{2}{|r|}{$Z 2$} & \multicolumn{2}{|c|}{ CPU time } \\
\hline & Lp-metric & Goal attainment & Lp-metric & Goal attainment & Lp-metric & Goal attainment \\
\hline \multirow{3}{*}{1} & 78369.20 & 78697.18 & 201432.54 & 201070.76 & 12.00 & 0.56 \\
\hline & 75381.67 & 73559.14 & 212578.88 & 224323.98 & 22.54 & 0.55 \\
\hline & 77078.28 & 75448.41 & 176402.33 & 187258.95 & 3.68 & 0.55 \\
\hline \multirow{3}{*}{2} & 62573.05 & 102072.43 & 263699.00 & 222953.83 & 8.38 & 0.64 \\
\hline & 56810.29 & 84869.33 & 307955.43 & 246879.21 & 14.35 & 0.50 \\
\hline & 66110.07 & 65413.24 & 211089.47 & 217681.99 & 12.25 & 0.23 \\
\hline \multirow{3}{*}{3} & 76223.75 & 74808.98 & 248822.61 & 256845.31 & 6.07 & 0.48 \\
\hline & 93058.09 & 89989.59 & 217589.47 & 238783.99 & 5.40 & 0.76 \\
\hline & 73882.59 & 72144.21 & 129470.59 & 146029.27 & 8.27 & 1.00 \\
\hline \multirow{3}{*}{4} & 61897.98 & 81583.77 & 355635.65 & 295536.59 & 5.04 & 1.40 \\
\hline & 55727.25 & 56358.74 & 229099.54 & 227986.23 & 2.67 & 0.27 \\
\hline & 84378.08 & 82747.18 & 210698.08 & 234744.31 & 10.62 & 1.64 \\
\hline \multirow{3}{*}{5} & 65822.17 & 67678.35 & 221625.42 & 218704.99 & 12.71 & 2.29 \\
\hline & 57347.17 & 76940.28 & 157334.02 & 151992.61 & 8.99 & 3.29 \\
\hline & 74451.73 & 73146.80 & 227127.30 & 235993.92 & 13.81 & 2.51 \\
\hline \multirow{3}{*}{6} & 80884.53 & 99706.93 & 464885.53 & 421627.99 & 9.88 & 3.01 \\
\hline & 88378.05 & 86944.41 & 426118.90 & 438370.60 & 19.25 & 2.62 \\
\hline & 77983.60 & 77252.66 & 338361.24 & 343318.83 & 7.92 & 7.27 \\
\hline \multirow{3}{*}{7} & 88554.12 & 88442.90 & 382064.04 & 382590.13 & 14.60 & 3.34 \\
\hline & 71868.39 & 85190.35 & 321585.63 & 311754.30 & 7.21 & 6.19 \\
\hline & 67813.34 & 67276.63 & 339081.46 & 342627.05 & 14.06 & 3.11 \\
\hline \multirow{3}{*}{8} & 74795.94 & 78480.46 & 323345.46 & 311931.54 & 7.38 & 2.72 \\
\hline & 83458.47 & 97864.26 & 414081.58 & 355688.73 & 8.36 & 5.20 \\
\hline & 62580.79 & 70956.41 & 339957.21 & 326584.42 & 10.78 & 4.51 \\
\hline \multirow{3}{*}{9} & 65279.95 & 78734.37 & 402703.93 & 341300.62 & 15.40 & 9.28 \\
\hline & 64500.04 & 92920.73 & 64500.04 & 271530.03 & 14.96 & 7.99 \\
\hline & 84421.85 & 83068.17 & 260279.55 & 280344.47 & 14.60 & 6.15 \\
\hline \multirow{3}{*}{10} & 91241.51 & 88457.49 & 253907.17 & 276414.50 & 17.75 & 2.92 \\
\hline & 86501.53 & 101732.42 & 386941.23 & 331216.12 & 9.44 & 2.34 \\
\hline & 80932.70 & 79857.07 & 247525.84 & 262327.25 & 1.89 & 0.50 \\
\hline \multirow{3}{*}{11} & 81553.46 & 81948.93 & 401917.11 & 399674.35 & 29.47 & 18.33 \\
\hline & 81952.34 & 112951.85 & 482179.51 & 425345.19 & 32.46 & 22.54 \\
\hline & 88288.06 & 86744.63 & 402062.76 & 414572.92 & 35.12 & 19.64 \\
\hline \multirow{2}{*}{12} & 103905.62 & 102545.93 & 467408.13 & 477137.12 & 12.78 & 0.52 \\
\hline & 75428.12 & 76452.68 & 483032.76 & 476819.06 & 14.85 & 6.07 \\
\hline \multirow{2}{*}{$13^{*}$} & 78413.44 & 119397.58 & 563847.56 & 513860.43 & 29.94 & 84.07 \\
\hline & 77655.55 & 78885.29 & 552931.62 & 544183.62 & 26.57 & 5.57 \\
\hline \multirow{2}{*}{$14^{*}$} & 86073.84 & 120078.02 & 602041.31 & 539802.79 & 26.16 & 6.47 \\
\hline & 85007.38 & 84693.62 & 442757.04 & 445505.45 & 9.63 & 5.51 \\
\hline
\end{tabular}

* GAMS software could not solve the sample problems by changing the parameters; for this reason, only two examples were solved.

were solved. Table 3 shows the results of the first and the second objective functions and CPU times in two Goal Attainment and Lp-metric techniques. The Goal Attainment and Lp-metric techniques are compared with using $Z 1, Z 2$, and $\mathrm{CPU}$ time criteria to find which technique is better. For this purpose, SAW and TOPSIS methods are used.

One of the best models of MADM (MultipleAttribute Decision Making) is TOPSIS (Technique for Order-Preference by Similarity to Ideal Solution) 
Table 4. Decision matrix.

\begin{tabular}{cccc}
\hline & $\boldsymbol{Z 1}$ & $\boldsymbol{Z 2}$ & CPU time \\
\hline Lp-metric & 76579.08 & 326514.79 & 13.82 \\
Goal attainment & 84513.88 & 321572.14 & 6.80 \\
\hline
\end{tabular}

Table 5. Results of SAW and TOPSIS methods.

\begin{tabular}{cccc}
\hline & Lp-metric & & Goal attainment \\
\hline SAW & 0.82 & $\leq$ & 0.96 \\
TOPSIS & 0.13 & $\leq$ & 0.24 \\
\hline
\end{tabular}

method. In this method, I alternatives are evaluated by $\mathrm{J}$ criteria. TOPSIS technique is based on the concept that the selected alternative should have the farthest distance from ideal negative solution (worst possible manner) and nearest distance from ideal positive solution (best possible manner). SAW is a simple scoring method, which is another method of MADM. The SAW method is based on the weighted average.

Table 4 shows decision matrix. Weights of the three criteria were assumed to be equal. After calculation, the results of the SAW and TOPSIS show that goal attainment is better than in Lp-metric technique, see Table 5 .

By increasing the size of the problems, GAMS software is not able to solve them. For this reason, we used genetic algorithm and simulated annealing (explained above) and solved them with Matlab software (R2013a).

For validation of genetic algorithm and simulated annealing, several sample problems with small sizes were solved by GAMS software, GA, and SA. Then, the results were compared, as shown in Tables 6 and 7 . The results show that the solution for the first and second objective functions $(Z 1$ and $Z 2)$ in three techniques (individual optimization, Lp-metric, goal attainment) is very small. Thus, the designed algorithms are valid.

Table 8 shows 30 problems with different dimensions used to solve the model with meta-heuristics and Matlab. Each problem was solved three times and mean of values was considered. Table 9 shows the results of $Z 1, Z 2$, and CPU time for solving the problems with genetic algorithm and simulated annealing for two Lp-metric and goal attainment MCDM techniques.

As an illustrative example, the results for the twenty-fifth sample problem are presented. In this sample problem, fifteen plants/stores, eight potential suppliers, and seven potential locations have been considered. After solving the model with genetic algorithm and goal attainment approach, these results were obtained. The third supplier is established in the seventh location and all of the plants/stores are
Table 6. Results of the first objective function $(Z 1)$ in $\mathrm{GA}$ and $\mathrm{SA}$ validations.

\begin{tabular}{|c|c|c|c|c|c|}
\hline \multirow[b]{2}{*}{ S.P } & \multicolumn{5}{|c|}{ Individual } \\
\hline & GAMS & GA & SA & $\begin{array}{c}\text { GA \% } \\
\text { gap }\end{array}$ & $\begin{array}{c}\text { SA \% } \\
\text { gap }\end{array}$ \\
\hline \multirow{2}{*}{6} & 65303.6 & 65303.6 & 65305.6 & 0 & 0 \\
\hline & 63073.9 & 63073.8 & 63074.6 & 0 & 0 \\
\hline \multirow{2}{*}{7} & 59256.1 & 59258.6 & 59258 & 0 & 0 \\
\hline & 63802.6 & 63802.8 & 63805.1 & 0 & 0 \\
\hline \multirow{2}{*}{8} & 58890 & 58890.5 & 58890 & 0 & 0 \\
\hline & 60622.6 & 60622.6 & 60624.2 & 0 & 0 \\
\hline \multirow{2}{*}{9} & 57116.5 & 57116.5 & 57120 & 0 & 0.01 \\
\hline & 56909.4 & 56909.4 & 56910.2 & 0 & 0 \\
\hline \multirow{2}{*}{10} & 69805.2 & 69805.2 & 69806.3 & 0 & 0 \\
\hline & 63802.6 & 63802.8 & 59152.9 & 0 & -7.29 \\
\hline \multirow[b]{2}{*}{ S.P. } & \multicolumn{5}{|c|}{ Lp-metric } \\
\hline & GAMS & GA & SA & $\begin{array}{c}\text { GA } \% \\
\text { gap }\end{array}$ & $\begin{array}{c}\text { SA \% } \\
\text { gap }\end{array}$ \\
\hline \multirow{2}{*}{6} & 72524.9 & 72479.4 & 72722.8 & -0.06 & 0.27 \\
\hline & 90108.6 & 90113.1 & 90585.5 & 0 & 0.53 \\
\hline \multirow{2}{*}{7} & 82903.4 & 82646.9 & 76326.4 & -0.31 & -7.93 \\
\hline & 65147.3 & 77360.2 & 65985.4 & 18.75 & 1.29 \\
\hline \multirow{2}{*}{8} & 63766.2 & 64612.7 & 64476.2 & 1.33 & 1.11 \\
\hline & 64253.1 & 64261.3 & 64171.4 & 0.01 & -0.13 \\
\hline \multirow{2}{*}{9} & 62323.9 & 62452.1 & 62645.3 & 0.21 & 0.52 \\
\hline & 70137.9 & 70978.9 & 70781.7 & 1.2 & 0.92 \\
\hline \multirow{2}{*}{10} & 75131.4 & 75236.6 & 75107 & 0.14 & -0.03 \\
\hline & 64711.8 & 64727.7 & 64136.3 & 0.02 & -0.89 \\
\hline \multirow[b]{2}{*}{ S.P. } & \multicolumn{5}{|c|}{ Goal attainment } \\
\hline & GAMS & GA & SA & $\begin{array}{c}\text { GA \% } \\
\text { gap }\end{array}$ & $\begin{array}{c}\text { SA \% } \\
\text { gap }\end{array}$ \\
\hline \multirow{2}{*}{6} & 72025.1 & 72090.8 & 73022.9 & 0.09 & 1.39 \\
\hline & 87224.5 & 87522.8 & 87792.9 & 0.34 & 0.65 \\
\hline \multirow{2}{*}{7} & 80829.8 & 81056.3 & 81335.1 & 0.28 & 0.63 \\
\hline & 70719.2 & 66368.9 & 74478.3 & -6.15 & 5.32 \\
\hline \multirow{2}{*}{8} & 80719.8 & 80523.2 & 80073.9 & -0.24 & -0.8 \\
\hline & 82604.3 & 82960.5 & 83097.7 & 0.43 & 0.6 \\
\hline \multirow{2}{*}{9} & 61732.8 & 61982.2 & 62044.9 & 0.4 & 0.51 \\
\hline & 69860 & 71672.6 & 70817.3 & 2.59 & 1.37 \\
\hline \multirow{2}{*}{10} & 101450.4 & 101456.3 & 101830.4 & 0.01 & 0.37 \\
\hline & 77990.4 & 78001.9 & 78138.5 & 0.01 & 0.19 \\
\hline
\end{tabular}


Table 7. Results of the second objective function $(Z 2)$ in GA and SA validations.

\begin{tabular}{|c|c|c|c|c|c|}
\hline \multirow[b]{2}{*}{ S.P } & \multicolumn{5}{|c|}{ Individual } \\
\hline & GAMS & GA & SA & $\begin{array}{c}\text { GA \% } \\
\text { gap }\end{array}$ & $\begin{array}{c}\text { SA \% } \\
\text { gap }\end{array}$ \\
\hline \multirow{2}{*}{6} & 263996.4 & 263652.2 & 263883.5 & -0.13 & -0.04 \\
\hline & 224859.7 & 224775 & 225201 & -0.04 & 0.15 \\
\hline \multirow{2}{*}{7} & 297429.9 & 297366.6 & 297652.5 & -0.02 & 0.07 \\
\hline & 250284.3 & 250692.8 & 251099.2 & 0.16 & 0.33 \\
\hline \multirow{2}{*}{8} & 375924.6 & 374022 & 378263.2 & -0.51 & 0.62 \\
\hline & 244031.5 & 243705.7 & 244122.4 & -0.13 & 0.04 \\
\hline \multirow{2}{*}{9} & 192738.5 & 191735.7 & 192122.5 & -0.52 & -0.32 \\
\hline & 294152.2 & 288300.9 & 288496.8 & -1.99 & -1.92 \\
\hline \multirow{2}{*}{10} & 265346.8 & 265662.1 & 266534.9 & 0.12 & 0.45 \\
\hline & 390185.8 & 390599 & 391055.8 & 0.11 & 0.22 \\
\hline \multirow[b]{2}{*}{ S.P. } & \multicolumn{5}{|c|}{ Lp-metric } \\
\hline & GAMS & GA & SA & $\begin{array}{c}\text { GA } \% \\
\text { gap }\end{array}$ & $\begin{array}{c}\text { SA \% } \\
\text { gap }\end{array}$ \\
\hline \multirow{2}{*}{6} & 268208.6 & 268706.7 & 266947.4 & 0.19 & -0.47 \\
\hline & 232161.4 & 232144.4 & 230662.9 & -0.01 & -0.65 \\
\hline \multirow{2}{*}{7} & 333543.1 & 306190.8 & 336889.7 & -8.2 & 1 \\
\hline & 252914.4 & 252505.1 & 249254.4 & -0.16 & -1.45 \\
\hline \multirow{2}{*}{8} & 396800.8 & 440861.6 & 442117.9 & 11.1 & 11.42 \\
\hline & 322545.6 & 322526.5 & 324197.7 & -0.01 & 0.51 \\
\hline \multirow{2}{*}{9} & 194277.8 & 193389.3 & 193100.9 & -0.46 & -0.61 \\
\hline & 305486.2 & 299680.7 & 301334 & -1.9 & -1.36 \\
\hline \multirow{2}{*}{10} & 344171.4 & 343998.1 & 344860.2 & -0.05 & 0.2 \\
\hline & 487072.6 & 487307.5 & 493349.3 & 0.05 & 1.29 \\
\hline \multirow[b]{2}{*}{ S.P. } & \multicolumn{5}{|c|}{ Goal attainment } \\
\hline & GAMS & GA & SA & $\begin{array}{c}\text { GA \% } \\
\text { gap }\end{array}$ & $\begin{array}{c}\text { SA \% } \\
\text { gap }\end{array}$ \\
\hline \multirow{2}{*}{6} & 270717.9 & 270457.8 & 270406.1 & -0.1 & -0.12 \\
\hline & 249010.3 & 249298.6 & 248662.1 & 0.12 & -0.14 \\
\hline \multirow{2}{*}{7} & 317176.9 & 317351.5 & 315807.4 & 0.06 & -0.43 \\
\hline & 256162.4 & 250260 & 253857.7 & -2.3 & -0.9 \\
\hline \multirow{2}{*}{8} & 406367 & 395797.6 & 402874.6 & -2.6 & -0.86 \\
\hline & 266013.2 & 266044.5 & 263722 & 0.01 & -0.86 \\
\hline \multirow{2}{*}{9} & 197354.8 & 196602.2 & 195913.7 & -0.38 & -0.73 \\
\hline & 307102.8 & 303035.4 & 300350.7 & -1.32 & -2.2 \\
\hline \multirow{2}{*}{10} & 296992 & 297293.6 & 292078.6 & 0.1 & -1.65 \\
\hline & 409024.6 & 409319.6 & 409411.3 & 0.07 & 0.09 \\
\hline
\end{tabular}

Table 8. Sample problems with different dimensions.

\begin{tabular}{cccccccc}
\hline $\begin{array}{c}\text { Sample } \\
\text { problem }\end{array}$ & $\boldsymbol{i}$ & $\boldsymbol{j}$ & $\boldsymbol{k}$ & $\begin{array}{c}\text { Sample } \\
\text { problem }\end{array}$ & $\boldsymbol{i}$ & $\boldsymbol{j}$ & $\boldsymbol{k}$ \\
\hline 1 & 6 & 3 & 2 & 16 & 12 & 6 & 6 \\
2 & 6 & 4 & 4 & 17 & 13 & 5 & 4 \\
3 & 7 & 4 & 3 & 18 & 13 & 6 & 5 \\
4 & 7 & 5 & 5 & 19 & 13 & 7 & 7 \\
5 & 8 & 5 & 4 & 20 & 14 & 4 & 3 \\
6 & 8 & 6 & 6 & 21 & 14 & 7 & 6 \\
7 & 9 & 4 & 3 & 22 & 14 & 8 & 8 \\
8 & 9 & 6 & 5 & 23 & 15 & 3 & 2 \\
9 & 9 & 7 & 7 & 24 & 15 & 5 & 4 \\
10 & 10 & 5 & 4 & 25 & 15 & 8 & 7 \\
11 & 10 & 7 & 6 & 26 & 15 & 9 & 9 \\
12 & 10 & 8 & 8 & 27 & 16 & 3 & 2 \\
13 & 11 & 4 & 3 & 28 & 16 & 4 & 3 \\
14 & 11 & 5 & 5 & 29 & 17 & 4 & 3 \\
15 & 12 & 5 & 4 & 30 & 18 & 5 & 4 \\
\hline
\end{tabular}

allocated to this supplier. Capacity of supplier 3 at site $7(\mathrm{P} 3,7)$ is equal to 48259 and order quantity for each supplier is, respectively, Q1 $=132$, Q2 $=207$, Q3 $=81, \mathrm{Q} 4=284, \mathrm{Q} 5=142, \mathrm{Q} 6=165, \mathrm{Q} 7=52, \mathrm{Q} 8=$ $229, \mathrm{Q} 9=344, \mathrm{Q} 10=303, \mathrm{Q} 11=44, \mathrm{Q} 12=154, \mathrm{Q} 13$ $=254, \mathrm{Q} 14=252, \mathrm{Q} 15=154$. Mean of costs (the first objective function) is $Z 1=221739.5$, variance of costs (the second objective function) is $Z 2=1605303$, and CPU time is 1133 sec.

To compare the performance of two algorithms, we used $Z 1, Z 2$, and CPU time criteria (Lp-metric and goal attainment techniques were compared separately). We used TOPSIS and SAW methods and statistical comparison in this section.

Tables 10 and 11 show decision matrices for the two techniques. Weights of the three criteria were assumed to be equal. The results show that in both techniques, simulated annealing is better than genetic algorithm, see Tables 12 and 13 . We used T-test with $\mathrm{P}$-value $=0.05$ for statistical comparisons and the calculations were performed with the SPSS20 software. The results showed that the means of $Z 1$ and $Z 2$ at two meta-heuristics did not have significant difference (sing $=0.503,0.783$ for Lp-metric and sing $=0.834,0.983$ for goal attainment), but the means of CPU time had a significant difference ( $\operatorname{sing}=0$ for both Lp-metric and Goal attainment), see Tables 14 and 15.

The amount of CPU time in simulated annealing is less than that in genetic algorithm and this criterion plays a very important role in excellence of simulated annealing in the genetic algorithm. The comparisons between $Z 1, Z 2$, and $\mathrm{CPU}$ time for $\mathrm{SA}$ and $\mathrm{GA}$ in each technique are presented in Figure 5. 
Table 9. Results of sample problems solved with the meta-heuristic and Matlab software.

\begin{tabular}{|c|c|c|c|c|c|c|c|c|c|c|c|c|}
\hline \multirow[b]{3}{*}{ S.P. } & \multicolumn{6}{|c|}{$\mathbf{L}_{\mathrm{P}}-$ Metric } & \multicolumn{6}{|c|}{ Goal attainment } \\
\hline & \multicolumn{3}{|c|}{ Genetic algorithm } & \multicolumn{3}{|c|}{ Simulated annealing } & \multicolumn{3}{|c|}{ Genetic algorithm } & \multicolumn{3}{|c|}{ Simulated annealing } \\
\hline & $Z 1$ & $Z 2$ & $\begin{array}{l}\text { CPU } \\
\text { time }\end{array}$ & $Z 1$ & $Z 2$ & $\begin{array}{l}\text { CPU } \\
\text { time }\end{array}$ & $Z 1$ & $Z 2$ & $\begin{array}{l}\text { CPU } \\
\text { time }\end{array}$ & $Z 1$ & $Z 2$ & $\begin{array}{l}\text { CPU } \\
\text { time }\end{array}$ \\
\hline 1 & 111316 & 666199.8 & 352 & 111601.8 & 686948.6 & 43 & 116802.8 & 658919.4 & 296 & 120452.3 & 659677.7 & 47 \\
\hline 2 & 85350.56 & 815663.2 & 357 & 85241.09 & 831163.7 & 44 & 116988.3 & 667219.8 & 412 & 123321.7 & 672362.9 & 41 \\
\hline 3 & 120121.6 & 1004373 & 258 & 120173.4 & 1031606 & 41 & 151668.2 & 841390.2 & 380 & 156832.3 & 829730.9 & 44 \\
\hline 4 & 92161.37 & 1089152 & 296 & 99823.35 & 1075225 & 49 & 147713.6 & 950962.6 & 300 & 149192 & 951025.2 & 48 \\
\hline 5 & 107088.2 & 1103056 & 310 & 107348.7 & 1143167 & 52 & 121556.3 & 1017019 & 323 & 126216.9 & 1011673 & 49 \\
\hline 6 & 106881.2 & 981270.3 & 345 & 108471.7 & 980949.9 & 56 & 148380.6 & 871596.6 & 365 & 146533.9 & 868391.6 & 58 \\
\hline 7 & 114236.5 & 1148340 & 533 & 113707.3 & 1190270 & 97 & 120401.9 & 1147627 & 522 & 122358.1 & 1146639 & 98 \\
\hline 8 & 106972.3 & 1086426 & 438 & 112783.6 & 1110021 & 57 & 149785.3 & 973248.6 & 365 & 158741.8 & 980148.3 & 60 \\
\hline 9 & 105602.1 & 952799.2 & 450 & 105997.5 & 979744.5 & 75 & 165677.7 & 898789.3 & 437 & 159552.6 & 899634 & 62 \\
\hline 10 & 120436.4 & 1591069 & 640 & 125246 & 1539498 & 111 & 157882.1 & 1324413 & 669 & 158641.8 & 1321445 & 115 \\
\hline 11 & 120959.8 & 1555807 & 465 & 123646.3 & 1568916 & 64 & 151849.7 & 1342203 & 519 & 163703 & 1395016 & 65 \\
\hline 12 & 106176 & 990601 & 507 & 106720.9 & 1009228 & 76 & 172929.5 & 977184 & 501 & 134594.9 & 948246.5 & 71 \\
\hline 13 & 128468 & 1034148 & 342 & 129079 & 1062740 & 52 & 139982 & 997897.7 & 337 & 144747.6 & 998636.1 & 53 \\
\hline 14 & 132887.4 & 1479758 & 630 & 143940.5 & 1414000 & 63 & 158692.3 & 1337603 & 787 & 179592.6 & 1375389 & 116 \\
\hline 15 & 131788 & 1409446 & 695 & 133146.8 & 1446710 & 127 & 144858.2 & 1401054 & 803 & 140849.5 & 1404656 & 93 \\
\hline 16 & 128415.1 & 1678481 & 850 & 136381.9 & 1611856 & 66 & 231897.9 & 1414346 & 727 & 182154.1 & 1361938 & 67 \\
\hline 17 & 144393.1 & 1218640 & 697 & 148052.4 & 1238450 & 71 & 161078.4 & 1116197 & 773 & 172749 & 1131822 & 79 \\
\hline 18 & 140820.8 & 1391234 & 439 & 156850.2 & 1300088 & 68 & 175483.8 & 1122810 & 439 & 184015.9 & 1106218 & 68 \\
\hline 19 & 128462.3 & 1739833 & 965 & 124071.1 & 1879146 & 147 & 227399.8 & 1601900 & 834 & 205244.4 & 1559139 & 118 \\
\hline 20 & 122735.6 & 1437541 & 800 & 126707.7 & 1432979 & 126 & 138735.1 & 1265117 & 811 & 154096.3 & 1296829 & 127 \\
\hline 21 & 136942 & 1832377 & 935 & 155138.6 & 1761580 & 160 & 160503 & 1634610 & 1059 & 169965.7 & 1626426 & 152 \\
\hline 22 & 133153.8 & 1569222 & 1165 & 128853.1 & 1755144 & 188 & 210568.5 & 1503785 & 1189 & 181660.6 & 1466525 & 188 \\
\hline 23 & 154889.6 & 1897515 & 680 & 159258.7 & 1892494 & 64 & 221593.9 & 1612890 & 676 & 235486.3 & 1623305 & 60 \\
\hline 24 & 149931.6 & 1967127 & 572 & 157951.2 & 1942434 & 87 & 209214.1 & 1583165 & 570 & 205501.8 & 1589100 & 73 \\
\hline 25 & 155216.7 & 1854720 & 1105 & 154433.1 & 2083120 & 181 & 221739.5 & 1605303 & 1133 & 217777.6 & 1632670 & 140 \\
\hline 26 & 143791.5 & 1735830 & 1138 & 151822.5 & 1711112 & 113 & 207597.3 & 1432004 & 1192 & 212644.5 & 1467300 & 168 \\
\hline 27 & 156875.5 & 1845484 & 509 & 161153.3 & 1928905 & 101 & 181292.2 & 1667965 & 441 & 191627.5 & 1691505 & 106 \\
\hline 28 & 146780.6 & 1975734 & 744 & 162321.9 & 1873334 & 98 & 261372.9 & 1794488 & 860 & 188109.8 & 1722377 & 74 \\
\hline 29 & 163226.5 & 2075764 & 650 & 163767 & 2322417 & 71 & 206382.2 & 1817243 & 700 & 217816 & 1848579 & 79 \\
\hline 30 & 172097.1 & 2120824 & 1089 & 170051.9 & 2365483 & 143 & 199939.1 & 1941822 & 767 & 217709.9 & 1998395 & 152 \\
\hline
\end{tabular}

Table 10. Lp-metric decision matrix.

\begin{tabular}{cccc}
\hline & $\boldsymbol{Z 1}$ & $\boldsymbol{Z 2}$ & $\begin{array}{c}\text { CPU } \\
\text { time }\end{array}$ \\
\hline Genetic algorithm & 128939.24 & 1441614.55 & 631.82 \\
Simulated annealing & 132791.41 & 1472291.00 & 89.76 \\
\hline
\end{tabular}

Table 11. Goal attainment decision matrix.

\begin{tabular}{cccc}
\hline & $\boldsymbol{Z 1}$ & $\boldsymbol{Z 2}$ & $\begin{array}{c}\text { CPU } \\
\text { time }\end{array}$ \\
\hline Genetic algorithm & 172665.54 & 1284025.74 & 639.52 \\
Simulated annealing & 170729.67 & 1286159.96 & 89.08 \\
\hline
\end{tabular}

Table 12. Results of SAW and TOPSIS methods for Lp-metric technique.

\begin{tabular}{cccc}
\hline & Genetic algorithm & \multicolumn{2}{c}{ Simulated annealing } \\
\hline SAW & 0.71 & $\leq$ & 0.97 \\
TOPSIS & 0.03 & $\leq$ & 0.97 \\
\hline
\end{tabular}

Table 13. Results of SAW and TOPSIS methods for Goal attainment technique.

\begin{tabular}{cccc}
\hline & Genetic algorithm & \multicolumn{2}{c}{ Simulated annealing } \\
\hline SAW & 0.70 & $\leq$ & 0.99 \\
TOPSIS & 0.001 & $\leq$ & 0.998 \\
\hline
\end{tabular}



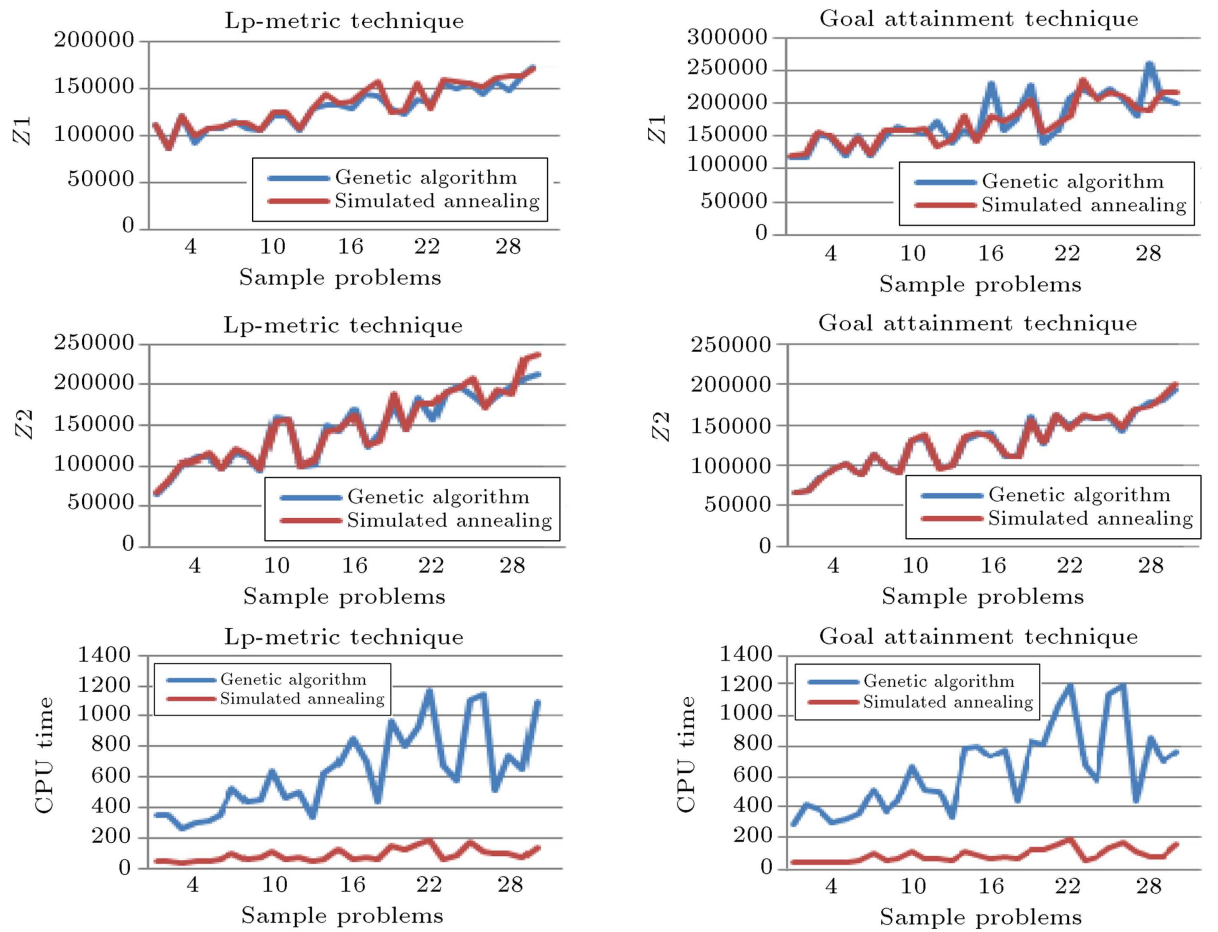

Figure 5. Comparison between the values of $Z 1, Z 2$, and CPU time for genetic algorithm and simulated annealing.

Table 14. Results of T-test for comparison genetic algorithm and simulated annealing (Lp-metric technique).

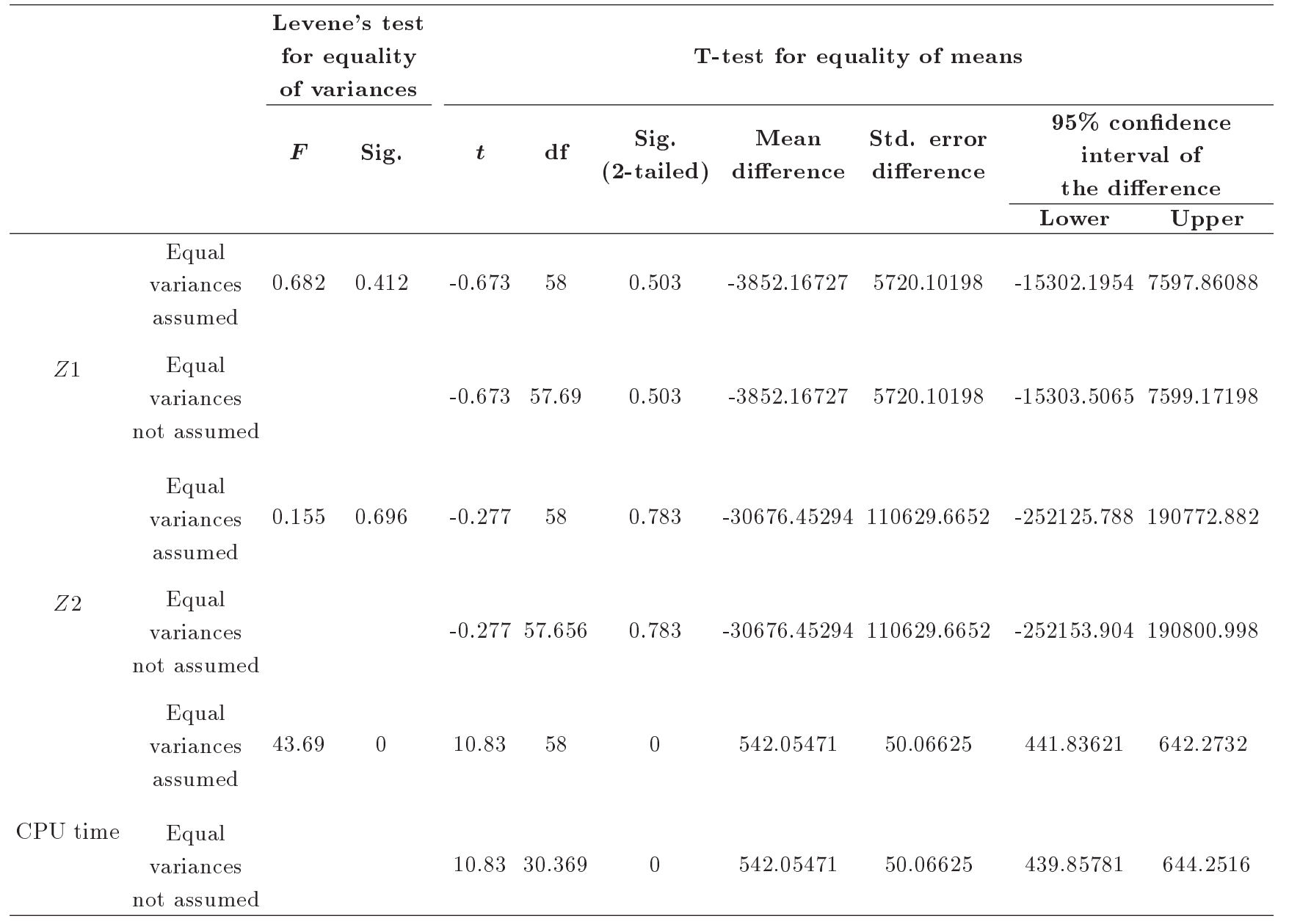


Table 15. Results of T-test for comparison genetic algorithm and simulated annealing (goal attainment technique).

\begin{tabular}{|c|c|c|c|c|c|c|c|c|c|c|}
\hline & & \multicolumn{2}{|c|}{$\begin{array}{c}\text { Levene's test } \\
\text { for equality } \\
\text { of variances } \\
\end{array}$} & \multicolumn{7}{|c|}{$\begin{array}{c}\text { T-test for } \\
\text { equality of means }\end{array}$} \\
\hline & & \multirow[t]{2}{*}{$F$} & \multirow[t]{2}{*}{ Sig. } & \multirow[t]{2}{*}{$t$} & \multirow[t]{2}{*}{ df } & \multirow[t]{2}{*}{$\begin{array}{c}\text { Sig. } \\
\text { (2-tailed) }\end{array}$} & \multirow[t]{2}{*}{$\begin{array}{c}\text { Mean } \\
\text { difference }\end{array}$} & \multirow[t]{2}{*}{$\begin{array}{l}\text { Std. error } \\
\text { difference }\end{array}$} & \multicolumn{2}{|c|}{$\begin{array}{c}95 \% \text { confidence } \\
\text { interval of } \\
\text { the difference }\end{array}$} \\
\hline & & & & & & & & & Lower & Upper \\
\hline \multirow{3}{*}{$Z 1$} & $\begin{array}{c}\text { Equal } \\
\text { variances } \\
\text { assumed }\end{array}$ & 1.226 & 0.273 & 0.211 & 58 & 0.834 & 1935.86234 & 9174.76957 & -16429.4343 & 20301.159 \\
\hline & $\begin{array}{c}\text { Equal } \\
\text { variances } \\
\text { not assumed }\end{array}$ & & & 0.211 & 56.267 & 0.834 & 1935.86234 & 9174.76957 & -16441.4861 & 20313.2108 \\
\hline & $\begin{array}{c}\text { Equal } \\
\text { variances } \\
\text { assumed }\end{array}$ & 0.004 & 0.948 & -0.023 & 58 & 0.981 & -2134.22001 & 91146.88006 & -184584.523 & 180316.083 \\
\hline \multirow[t]{2}{*}{$Z 2$} & $\begin{array}{c}\text { Equal } \\
\text { variances } \\
\text { not assumed }\end{array}$ & & & -0.023 & 57.992 & 0.981 & -2134.22001 & 91146.88006 & -184585.041 & 180316.601 \\
\hline & $\begin{array}{c}\text { Equal } \\
\text { variances } \\
\text { assumed }\end{array}$ & 54.37 & 0 & 11.06 & 58 & 0 & 550.43964 & 49.75211 & 450.84997 & 650.02932 \\
\hline CPU time & $\begin{array}{c}\text { Equal } \\
\text { variances } \\
\text { not assumed }\end{array}$ & & & 11.06 & 30.298 & 0 & 550.43964 & 49.75211 & 448.87421 & 652.00508 \\
\hline
\end{tabular}

\section{Conclusions and suggestions}

In this paper, a novel model for integrating the facility (supplier) location-allocation problem and supplier selection-order allocation for a two-echelon supply chain (supplier(s) and plant(s)/store(s)) was proposed. This model also determined the inventory policy for each plant/store (when and how much to order at each plant/store). Therefore, the proposed bi-objective mixed-integer nonlinear programming was solved using two MODM methods by GAMS software for small-size and meta-heuristic algorithms (genetic algorithm and simulated annealing) by Matlab software for medium and large sizes. Numerical examples with different sizes were provided to demonstrate the application and to compare the performances of the investigated solution methods in terms of mean and variance of the overall supply chain costs and required CPU time. The results showed that goal attainment had better performance than Lp-metric technique for small sizes. For large sizes, the comparisons showed that the means of objective functions ( $Z 1$ and $Z 2$ ) obtained from GA and SA did not have significant differences, but the mean of SA-CPU time was significantly less than that of the GA-CPU time. Thus, the simulated annealing had better performance than the genetic algorithm.

Design of a Model with fuzzy or stochastic demand or use of De Novo programming to determine the capacity of the supplier are suggested for future research. Moreover, NSGA-II, NRGA, and MOPSO algorithms can be used to solve the model.

\section{References}

1. JABAL-AMELI, M., Shahanaghi, K., Hosnavi, R. and Nasiri, M. "A combined model for locating critical centers (HAPIT)", International Journal of Industrial Engineering and Production Management (International Journal of Engineering Science) (PERSIAN), (2010).

2. Weber, A. and Friedrich, C.J., Weber's Theory of the Location of Industries, Chicago University Press (1929).

3. Cooper, L. "Location-allocation problems", Operations Research, 11(3), pp. 331-343 (1963).

4. Hosage, C. and Goodchild, M. "Discrete space location-allocation solutions from genetic algorithms", Annals of Operations Research, 6(2), pp. 35-46 (1986). 
5. Medaglia, A.L., Villegas, J.G. and Rodríguez-Coca, D.M. "Hybrid biobjective evolutionary algorithms for the design of a hospital waste management network", Journal of Heuristics, 15(2), pp. 153-176 (2009).

6. Uno, T., Hanaoka, S. and Sakawa, M. "An application of genetic algorithm for multi-dimensional competitive facility location problem", Systems, Man and Cybernetics, IEEE International Conference on, pp. 32763280 (2005).

7. Yang, J., Xiong, J., Liu, S. and Yang, C. "Flow capturing location-allocation problem with stochastic demand under hurwicz rule", Natural Computation, ICNC'08. Fourth International Conference on, pp. 169-173 (2008).

8. Murtagh, B. and Niwattisyawong, S. "An efficient method for the multi-depot location-allocation problem", Journal of the Operational Research Society, pp. 629-634 (1982).

9. Hosseininezhad, S.J., Jabalameli, M.S. and Naini, S.G.J. "A fuzzy algorithm for continuous capacitated location allocation model with risk consideration", Applied Mathematical Modelling, 38(3), pp. 983-1000 (2014).

10. Mestre, A.M., Oliveira, M.D. and Barbosa-Póvoa, A.P. "Location-allocation approaches for hospital network planning under uncertainty", European Journal of Operational Research, 240(3), pp. 791-806 (2015).

11. Mousavi, S.M. and Niaki, S.T.A. "Capacitated location allocation problem with stochastic location and fuzzy demand: A hybrid algorithm", Applied Mathematical Modelling, 37(7), pp. 5109-5119 (2013).

12. Vidyarthi, N. and Jayaswal, S. "Efficient solution of a class of location-allocation problems with stochastic demand and congestion", Computers \& Operations Research, 48, pp. 20-30 (2014).

13. Owen, S.H. and Daskin, M.S. "Strategic facility location: A review", European Journal of Operational Research, 111(3), pp. 423-447 (1998).

14. Ho, W., Lee, C.K.M. and Ho, G.T.S. "Optimization of the facility location-allocation problem in a customerdriven supply chain", Operations Management Research, 1(1), pp. 69-79 (2008).

15. Melo, M.T., Nickel, S. and Saldanha-da-Gama, F. "Facility location and supply chain management-A review", European Journal of Operational Research, 196(2), pp. 401-412 (2009).

16. Wang, K.-J., Makond, B. and Liu, S.-Y. "Location and allocation decisions in a two-echelon supply chain with stochastic demand-A genetic-algorithm based solution", Expert Systems with Applications, 38(5), pp. 6125-6131 (2011).

17. Ahmadi Javid, A. and Azad, N. "Incorporating location, routing and inventory decisions in supply chain network design", Transportation Research Part E:
Logistics and Transportation Review, 46(5), pp. 582597 (2010).

18. Mangotra, D., Lu, J.-C. and Tsao, Y.-C., A Continuous Approximation Approach for the Integrated Facility-Inventory Allocation Problem (2009).

19. Amin, S.H. and Zhang, G. "A multi-objective facility location model for closed-loop supply chain network under uncertain demand and return", Applied Mathematical Modelling, 37(6), pp. 4165-4176 (2013).

20. Weber, C.A. and Current, J.R. "A multiobjective approach to vendor selection", European Journal of Operational Research, 68(2), pp. 173-184 (1993).

21. Weber, C.A., Current, J.R. and Benton, W. "Vendor selection criteria and methods", European Journal of Operational Research, 50(1), pp. 2-18 (1991).

22. Degraeve, Z., Labro, E. and Roodhooft, F. "An evaluation of vendor selection models from a total cost of ownership perspective", European Journal of Operational Research, 125(1), pp. 34-58 (2000).

23. Minner, S. "Multiple-supplier inventory models in supply chain management: A review", International Journal of Production Economics, 81, pp. 265-279 (2003).

24. Aissaoui, N., Haouari, M. and Hassini, E. "Supplier selection and order lot sizing modeling: A review", Computers \& operations research, 34(12), pp. 35163540 (2007).

25. Keskin, B.B., Üster, H. and Çetinkaya, S. "Integration of strategic and tactical decisions for vendor selection under capacity constraints", Computers \& Operations Research, 37(12), pp. 2182-2191 (2010).

26. Basnet, C. and Leung, J.M. "Inventory lot-sizing with supplier selection", Computers \& Operations Research, 32(1), pp. 1-14 (2005).

27. Ghodsypour, S.H. and O'brien, C. "The total cost of logistics in supplier selection, under conditions of multiple sourcing, multiple criteria and capacity constraint", International Journal of Production Economics, 73(1), pp. 15-27 (2001).

28. Tempelmeier, H. "A simple heuristic for dynamic order sizing and supplier selection with time-varying data", Production and Operations Management, 11(4), pp. 499-515 (2002).

29. Snyder, L.V., Daskin, M.S. and Teo, C.-P. "The stochastic location model with risk pooling", European Journal of Operational Research, 179(3), pp. 12211238 (2007).

30. Üster, H., Keskin, B.B. and Çetinkaya, S. "Integrated warehouse location and inventory decisions in a threetier distribution system", IIE Transactions, 40(8), pp. 718-732 (2008).

31. Kuenne, R.E. and Soland, R.M. "Exact and approx- 
imate solutions to the multisource Weber problem", Mathematical Programming, 3(1), pp. 193-209 (1972).

32. Belenguer, J.-M., Benavent, E., Prins, C., Prodhon, C. and Wolfler Calvo, R. "A branch-and-cut method for the capacitated location-routing problem", Computers \& Operations Research, 38(6), pp. 931-941 (2011).

33. Marín, A. "The discrete facility location problem with balanced allocation of customers", European Journal of Operational Research, 210(1), pp. 27-38 (2011).

34. Sourirajan, K., Ozsen, L. and Uzsoy, R. "A singleproduct network design model with lead time and safety stock considerations", IIE Transactions, 39(5), pp. 411-424 (2007).

35. Miranda, P.A. and Garrido, R.A. "Valid inequalities for Lagrangian relaxation in an inventory location problem with stochastic capacity", Transportation Research Part E: Logistics and Transportation Review, 44(1), pp. 47-65 (2008).

36. Cordeau, J.-F., Pasin, F. and Solomon, M.M. "An integrated model for logistics network design", Annals of Operations Research, 144(1), pp. 59-82 (2006).

37. Geoffrion, A. and Graves, G. "Multicommodity distribution system design by benders decomposition", A Long View of Research and Practice in Operations Research and Management Science, International Series in Operations Research \& Management Science, 148 pp. 35-61 (2010).

38. Tuzun, D. and Burke, L.I. "A two-phase tabu search approach to the location routing problem", European Journal of Operational Research, 116(1), pp. 87-99 (1999).

39. Lee, D.-H. and Dong, M. "A heuristic approach to logistics network design for end-of-lease computer products recovery", Transportation Research Part E: Logistics and Transportation Review, 44(3), pp. 455474 (2008).

40. Ko, H.J. and Evans, G.W. "A genetic algorithm-based heuristic for the dynamic integrated forward/reverse logistics network for 3PLs", Computers \& Operations Research, 34(2), pp. 346-366 (2007).

41. Fernandes, D.R., Rocha, C., Aloise, D., Ribeiro, G.M., Santos, E.M. and Silva, A. "A simple and effective genetic algorithm for the two-stage capacitated facility location problem", Computers \& Industrial Engineering, 75, pp. 200-208 (2014).

42. Jayaraman, V., Patterson, R.A. and Rolland, E. "The design of reverse distribution networks: models and solution procedures", European Journal of Operational Research, 150(1), pp. 128-149 (2003).

43. Bashiri, M. and Bakhtiarifar, M. "Finding the optimum location in a one-median network problem with correlated demands using simulated annealing", Scientia Iranica, 20(3), pp. 793-800 (2013).

44. Keskin, B.B. and Üster, H. "Meta-heuristic approaches with memory and evolution for a multi-product production/distribution system design problem", Euro- pean Journal of Operational Research, 182(2), pp. 663682 (2007).

45. Keskin, B.B. and Üster, H. "A scatter search-based heuristic to locate capacitated transshipment points", Computers \& Operations Research, 34(10), pp. 31123125 (2007).

46. Jang, Y.-J., Jang, S.-Y., Chang, B.-M. and Park, J. "A combined model of network design and production/distribution planning for a supply network", Computers \& Industrial Engineering, 43(1), pp. 263281 (2002).

47. Gembicki, F. "Vector optimization for control with performance and parameter sensitivity indices", Ph.D. Thesis, Case Western Reserve Univ., Cleveland, Ohio (1974).

48. Zeleny, M. and Cochrane, J.L., Multiple Criteria Decision Making (1982).

49. Duckstein, L. and Opricovic, S. "Multiobjective optimization in river basin development", Water Resources Research, 16(1), pp. 14-20 (1980).

50. Szidarovszky, F., Gershon, M.E. and Duckstein, L., Techniques for Multiobjective Decision Making in Systems Management (1986).

51. Fraser, A.S. "Simulation of genetic systems by automatic digital computers vi. epistasis", Australian Journal of Biological Sciences, 13(2), pp. 150-162 (1960).

52. Bremermann, H.J., The Evolution of Intelligence: The Nervous System as a Model of Its Environment (1958).

53. Holland, J.H., Adaptation in Natural and Artificial Systems: An Introductory Analysis with Applications to Biology, Control, and Artificial Intelligence, The MIT Press (1975).

54. Kirkpatrick, S., Gelatt, C.D. and Vecchi, M.P. "Optimization by simmulated annealing", Science, 220(4598), pp. 671-680 (1983).

55. Černý, V. "Thermodynamical approach to the traveling salesman problem: An efficient simulation algorithm", Journal of Optimization Theory and Applications, 45(1), pp. 41-51 (1985).

\section{Biographies}

Fatemeh Ranjbar Tezenji obtained a BS degree in Materials Engineering from Islamic Azad University, Meybod, Iran, in 2001, and an MS degree in Industrial Engineering from Kharazmi University, Tehran, Iran, in 2015. Her research interests include supply chain management, inventory management, quality management, project scheduling and management, and artificial intelligence techniques.

Mohammad Mohammadi is a faculty member in the Department of Industrial Engineering, Kharazmi 
University, Tehran, Iran. He received his BS in Industrial Engineering from Iran University of Science and Technology, Tehran, Iran, in 2000 and his MS and $\mathrm{PhD}$ in Industrial Engineering from Amirkabir University of Technology, Tehran, Iran, in 2002 and 2009, respectively. His research and teaching interests include sequencing and scheduling, production planning, time series, meta-heuristics, and supply chains.

Seyed Hamid Reza Pasandideh obtained his BSc, $\mathrm{MSc}$, and $\mathrm{PhD}$ in Industrial Engineering from Sharif University of Technology. He is currently an Assistant Professor in the Department of Industrial Engineering at Kharazmi University. His research is concentrated on optimization methods and inventory control. He is editor and reviewer of some international journals.

Mehrdad Nouri Koupaei obtained his BS degree in Industrial Engineering from Islamic Azad University, Iran, in 2009, and MS degree in Industrial Management from Islamic Azad University, Iran, in 2011. He is currently $\mathrm{PhD}$ candidate of Industrial Engineering in the Department of Faculty of Engineering at Kharazmi University, Iran. His research interests include optimization methods, and scheduling and meta-heuristic algorithms. He has published and presented numerous papers in various journals and national and international conferences. 